\title{
蒟蒻マンナン分解に関与する腸內細菌に関する研究
}

\section{On the Intestinal Bacilli related to the Decomposition of Konnyaku Mannan}

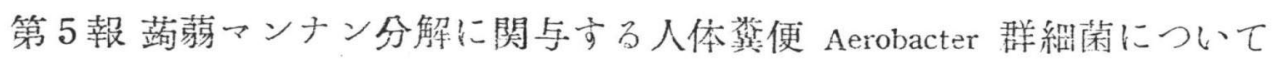

Five Reports On the Bacteria beloging to the Aerobacter group of Human Fec ss related to the Decomposition of Konnyaku Mannan

国立栄䍱研究那 (National Institute of Nutrition)

$$
\text { 烡上 畫 政 (Norimasa Inoue) }
$$

道立䇶生研攽所 (Hokikaido Institute of Public Health)

$$
\text { 半上腾玧 (Katsuhiro Inoue) }
$$

The opinion that Konnyaku mannan is not digested in the digestive canal systam of the higher class animals is nearly consistant. Formerly the author isolated 2 strains of coliform bacteria which decompose Konnyaku mannan from among 32 strains of coliform group, which were is olated from sent 8 samples of human feces. Their properties and statuses wer a test ad and identified to be Arrobacter cloacae formi.

In this report were testad frequency of appearance of Aerobactar group and Konnyaku mannan $\mathrm{d}$ composing Aerobacter group and biclogical properties of the isolated strains.

Ratio of apparance of Konnyaku manran decomposing Aerobacter group to Aerobacter group varies between $1 / 10$ and $1 / 100$, and the majority lies in approximat ly $1 / 100$.

All of the isolated bacteria are lactose fermentable and non spor ad bacteria, and IMVIC system (Paar) is - ++ . They belong to the Aero acter cloacae type. It is suggested that this variety of Aerobacter cloacae group exists in human intestines, decomposes Konnyaku mannan and contribute to human nutrition. It is evident that intestinal bacteria in human being are not foreign element material nor symbiotic existence, but conjugative existence.

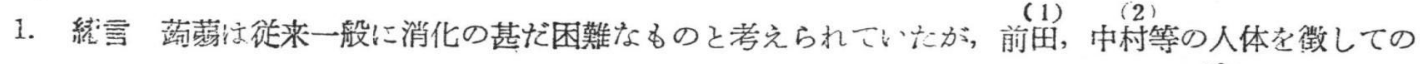

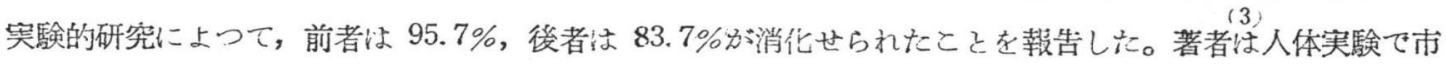

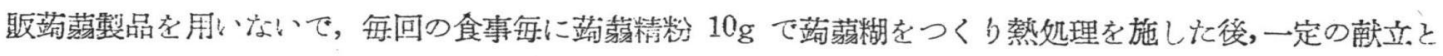

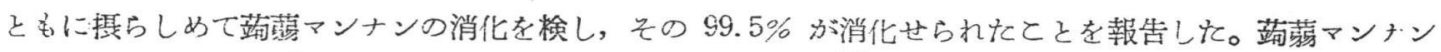

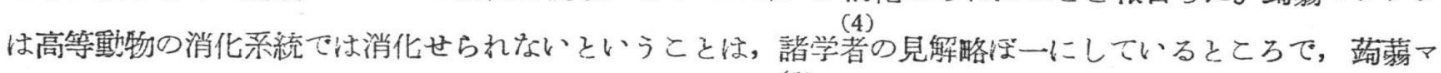
ンナンの人体での消化は腸内細菌の作用に帰着する。著者は澺に8 例の入雚便から分離した Coliform 群細

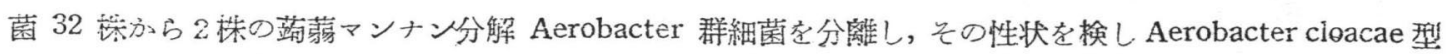
であるとと在確め灾。

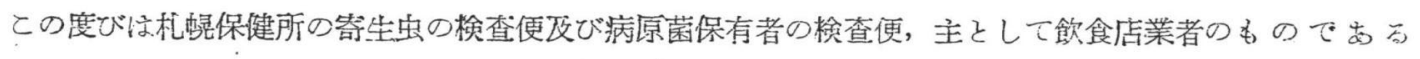

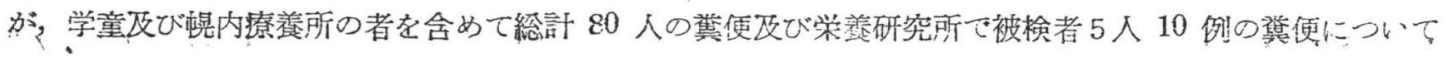




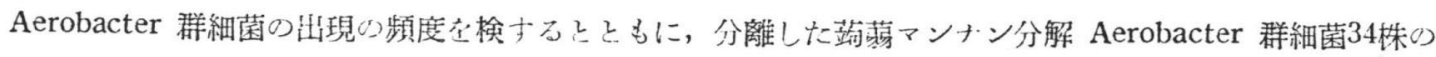
性状を検した。

2. Aerobacter 群細菌及び蒟荡マンナン分解 Aerobacter 群細菌の出現の頻度 試料便 $1 \mathrm{~g}$ 在 $9 \mathrm{cc}$ の Koser 培地に投じ, 隇菌海砂の少量走加光, 隇菌硝子棒にて磨砕振盪して 10-1 倍稀釈便液走つくり, その $1 \mathrm{cc}$ を $9 \mathrm{cc}$ の Koser 培地に投じ 10-2 倍稀橎便液をつくり，10 進法によつて 10-8 倍稀釈便液まで

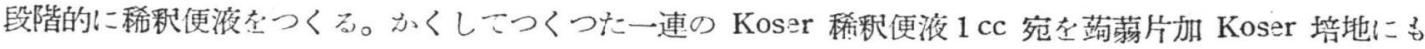

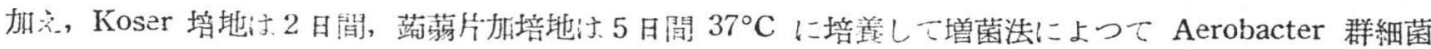

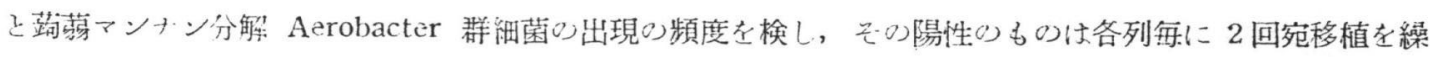

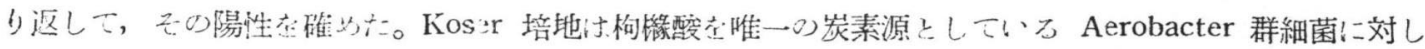
ての撰択培地ておる。

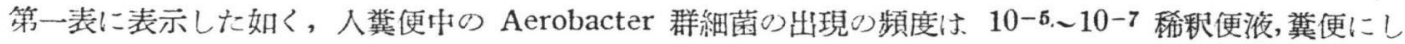

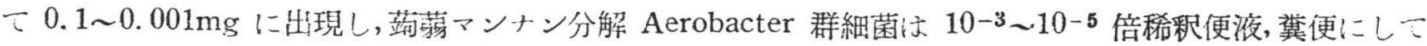
10.0〜0.1mgに出現方る蓓蒙マンナン分解 Aerobacter 群細菌の Aerobacter 群䋑菌に対する出現の比

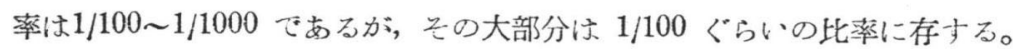

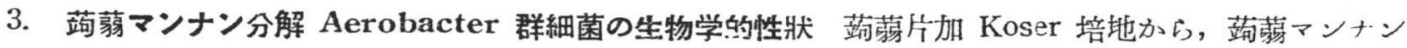
在分解する Aerobacter 君細菌を Table 1 Frequency of apearance of Aerobacter 検索分離するには，端藏マンナン 在分解した培抑立更! 2 2 3 回宛 移植を繰り返してから，生理的食

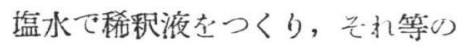
稀彩液高Endo平板に淕抹培善し， 出来るだけ多くの聚落在釣菌して

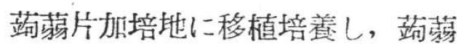
マンナンを分解するAerobacter 群細菌を検索分離し，更に平板に 純粋培盖在繰り返し、眝蔵菌株と し，その性状を検した。

分離菌株は第 2 ～ 3 表に表示し た如く、いずれ年短桿菌て，ダラ 八染色陰性, 盷子一, Modified Eijkman test-, Imvic System (Paar) - - + + て定型的A eroba cter 群細菌に属し，乳糖交緩徐に 䣭酵し，グリセリン岕らガス在生 ずることなく，馬晨酸ソーダ分解 一，ゼラチンを緩徐に分解するこ と等から Aerobacter cloacae 型 group and Konnyaku mannan decomposing Aerobacter group

\begin{tabular}{|c|c|c|c|c|c|}
\hline \multirow{2}{*}{$\begin{array}{c}\text { Tested } \\
\text { man }\end{array}$} & \multicolumn{3}{|c|}{ Koser medium } & \multicolumn{2}{|c|}{$\begin{array}{c}\text { Konnyaku flake added } \\
\text { Koser medium }\end{array}$} \\
\hline & Feces & dilution & Feces amt. mg. & Feces dilution & Feces amt. mg. \\
\hline Ki. I & & $10-6$ & 0.01 & $10-3$ & 10.0 \\
\hline Ki. II & & $10^{-5}$ & 0.1 & $10^{-4}$ & 1.0 \\
\hline Ka. I & & $10^{-5}$ & 0.1 & $10^{-3}$ & 10.0 \\
\hline Ka. II & & $10-5$ & 0.1 & $10^{-3}$ & 10.0 \\
\hline Su. I & & $10^{-5}$ & 0.1 & $10^{-3}$ & 10.0 \\
\hline Su. II & & $10-5$ & 0.1 & $10^{-3}$ & 10.0 \\
\hline Ic. 1 & & $10-7$ & 0.001 & $10^{-3}$ & 10.0 \\
\hline Ic. II & & $10^{-6}$ & 0.01 & $10^{-3}$ & 10.0 \\
\hline Ha. I & & $10-7$ & 0.001 & $10-5$ & 0.1 \\
\hline Ha. II & & $10-6$ & 0.01 & $10^{-4}$ & 1.0 \\
\hline Sa. 7 & & $10-5$ & 0.1 & $10^{-3}$ & 10.0 \\
\hline Sa. 13 & & $10^{-7}$ & 0.001 & $10-5$ & 0.1 \\
\hline Sa. 69 & & $10^{-6}$ & 0.01 & $10^{-4}$ & 1.0 \\
\hline Sa. 76 & & $10-7$ & 0.001 & $10^{-5}$ & 0.1 \\
\hline Sa. 79 & & $10^{-5}$ & 0.1 & $10^{-3}$ & 10.0 \\
\hline
\end{tabular}


Table 2 Biological properties of the isolated Kormyahu

\begin{tabular}{|c|c|c|c|c|c|c|c|c|c|c|c|c|c|c|c|}
\hline & do & $\begin{array}{r}.5 \\
+5 \\
+5\end{array}$ & 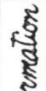 & & & & $M$ & $\checkmark i c$ & & & & & & us & కీ \\
\hline ô $\frac{3}{3}$ & हैं & 这 & \begin{tabular}{r}
3 \\
\multirow{2}{2}{} \\
2 \\
\end{tabular} & $\frac{1}{2}$ & & & & & & & & & 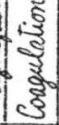 & 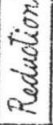 & $\frac{13}{2}$ \\
\hline Hi. I $10^{-2}-1$ & $\operatorname{Rod}$ & - & - & + & + & - & 一 & + & + & - & - & & $t^{10}$ & & + \\
\hline K!. I $10^{-2}-2$ & + & - & - & + & + & - & 一 & + & + & - & 一 & & +9 & +10 & i- \\
\hline ki. I $10^{-2}-3$ & - & - & - & + & + & - & - & $t$ & + & 一 & - & - & +10 & & t- \\
\hline$K_{i} \cdot I 10^{-3}-1$ & ' & - & - & t- & + & - & - & + & + & - & - & - & +10 & +10 & + \\
\hline Ki. If $10^{-3}-2$ & s & - & - & + & + & - & - & + & 4 & - & - & , & +8 & +8 & + \\
\hline Ki. I $10^{-3}-3$ & $s$ & - & - & + & $t$ & - & - & + & t- & 一 & - & 4 & +9 & +-10 & $t$ \\
\hline K1. $10^{-3}-4$ & , & - & - & + & + & - & - & $t$ & + & - & - & - & +7 & +7 & $t$ \\
\hline $\mathrm{Ki} . \mathrm{I} 10^{-3}-5$ & ' & - & - & t- & + & - & - & + & + & 一 & - & 8 & +9 & +10 & + \\
\hline Ki. $10^{-3}-6$ & 4 & 一 & - & + & + & - & - & + & + & - & - & ' & +8 & +10 & + \\
\hline Ka. I $10^{-2}-1$ & - & - & - & + & + & - & - & + & + & - & - & 5 & +8 & +9 & + \\
\hline Ka. I, $10^{2}-2$ & ' & 一 & - & fetel & + & - & - & + & + & 一 & - & ‘ & +7 & +7 & $t$ \\
\hline Ka.I $10^{-2}-3$ & $\therefore$ & - & - & + & $t$ & - & - & + & + & 一 & - & 6 & +8 & +9 & + \\
\hline Ka. I $10^{-2}-1$ & $\therefore$ & - & - & + & + & - & - & + & + & - & - & & +9 & +7 & + \\
\hline Ka. I $10^{-2}-2$ & • & 一 & 一 & + & + & - & - & + & $t-$ & - & - & & +7 & +7 & + \\
\hline $\mathrm{Ka} \cdot \overline{1} 10^{2}-\overline{3}$ & 3 & - & - & + & + & - & - & + & + & - & - & 4 & +8 & +8 & + \\
\hline Su. I $10^{-2}-1$ & ' & - & - & + & + & - & - & $t$ & + & - & - & 4 & +6 & +5 & $t$ \\
\hline Su. I $10^{-2}-2$ & , & - & - & + & + & - & - & + & + & - & - & + & +3 & +5 & + \\
\hline Su. I $10^{-2}-1$ & -1 & - & - & t- & + & - & - & $t$ & + & - & - & ' & +3 & +5 & + \\
\hline$S u$. II $10^{2}-2$ & 4 & 一 & - & + & $t$ & - & - & + & + & - & - & 4 & +3 & +5 & + \\
\hline Su. I $10^{-2}-3$ & , & - & - & + & + & - & - & $t$ & + & - & - & ‘ & +3 & +5 & + \\
\hline Ic. $1.10^{-3}-1$ & ‘ & 一 & - & + & + & - & - & + & $t$ & - & - & ， & +5 & +8 & + \\
\hline I c. I $10^{-3}-2$ & • & - & - & + & + & - & - & + & \pm & - & - & rat & +8 & +8 & + \\
\hline I c. $110^{-3}-1$ & 4 & - & - & + & + & - & - & + & + & - & - & & +8 & +8 & + \\
\hline I c. $10^{-3}-2$ & 6 & - & - & + & + & - & - & $t$ & + & - & - & s & +8 & +8 & + \\
\hline $\mathrm{Ha} \cdot 10^{-3}-1$ & ' & 一 & - & + & + & - & - & + & + & - & - & r & +8 & +8 & + \\
\hline Ha.I $10^{3}-2$ & 4 & - & - & + &.+ & - & - & + & + & - & - & s & +8 & +8 & + \\
\hline$H$ a. I $10^{3}-3$ & $\therefore$ & - & - & + & + & - & - & + & + & - & - & : & +7 & +7 & + \\
\hline $\mathrm{Ha} . \mathrm{I} 10^{-3}-1$ & $:$ & - & - & + & + & - & - & $t$ & + & - & - & , & +9 & +9 & $\because$ \\
\hline Ha I I $10^{3}-2$ & 6 & - & - & + & + & - & - & + & + & - & - & , & +8 & +9 & + \\
\hline $\mathrm{Ha}$. II $10^{3}-3$ & 4 & - & - & + & + & - & - & + & + & - & - & : & +8 & +10 & + \\
\hline \$a. 7 & 4 & - & - & + & t. & - & - & t. & $\frac{1}{1}$ & - & - & * & +5 & +7 & + \\
\hline 9 a. is & : & - & - & + & + & - & - & t. & + & - & - & 4 & +7 & +8 & + \\
\hline 3 a. 76 & $\cdot$ & - & - & + & + & - & - & 4 & + & - & - & , & +8 & +9 & + \\
\hline 32.79 & $\therefore 1$ & - & - & + & + & $=2$ & - & + & + & - & - & 3 & $t^{8}$ & +9 & + \\
\hline
\end{tabular}

備考: E. C. 詰験す Modified Eijkman test 上同成績

の異型菌であるこ在確認した。抑もAerobacter cioacae 型で難消化物たる蕗芴マンナンを分解する株の

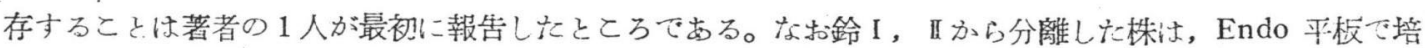
盖 1 日目の所見ては, その聚落が Endo 平板を赤変し, その他の株の淡桃色の聚落と異つており, 乳糖を 比較的に他の株に二比してやや速汃に分解した。

4. 票約 各人の人体腸内には, 人体の消化液の全力を以てしても消化せられない難消化物方踦蒻マン

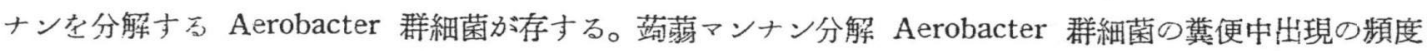
は 10-3〜10-5 倍稀积便液, 䔬便にしての 10〜0.1mg てある。端蒻マンナン分解 Aerobacter 群細菌の Aerobacter群細菌々の出現の比率は1/100１000 であるが，その大部分は1/100ぐらいの比率である。分離 した端蒙マンナン分解Aerobacter 群細菌34株は, 尖の生物学的性状はいずれる同一で Aerobacter cloacae 型の異型菌である。この種細菌が各人の腸内に存し，難消化物在消化し，人体の栄盖に貢献していることが 窥知される。かかる意味合からしても, 人体の腸内細菌法決して単なる異物的存在, 寄生的存在てはなく共 生的意義を持つるのなることは疑を入れない。

1) 前田実: 東京医学会雑誌，25，518 (1911) 
Table 3 Fismertation of caibofudrates alcohols, glecoside.

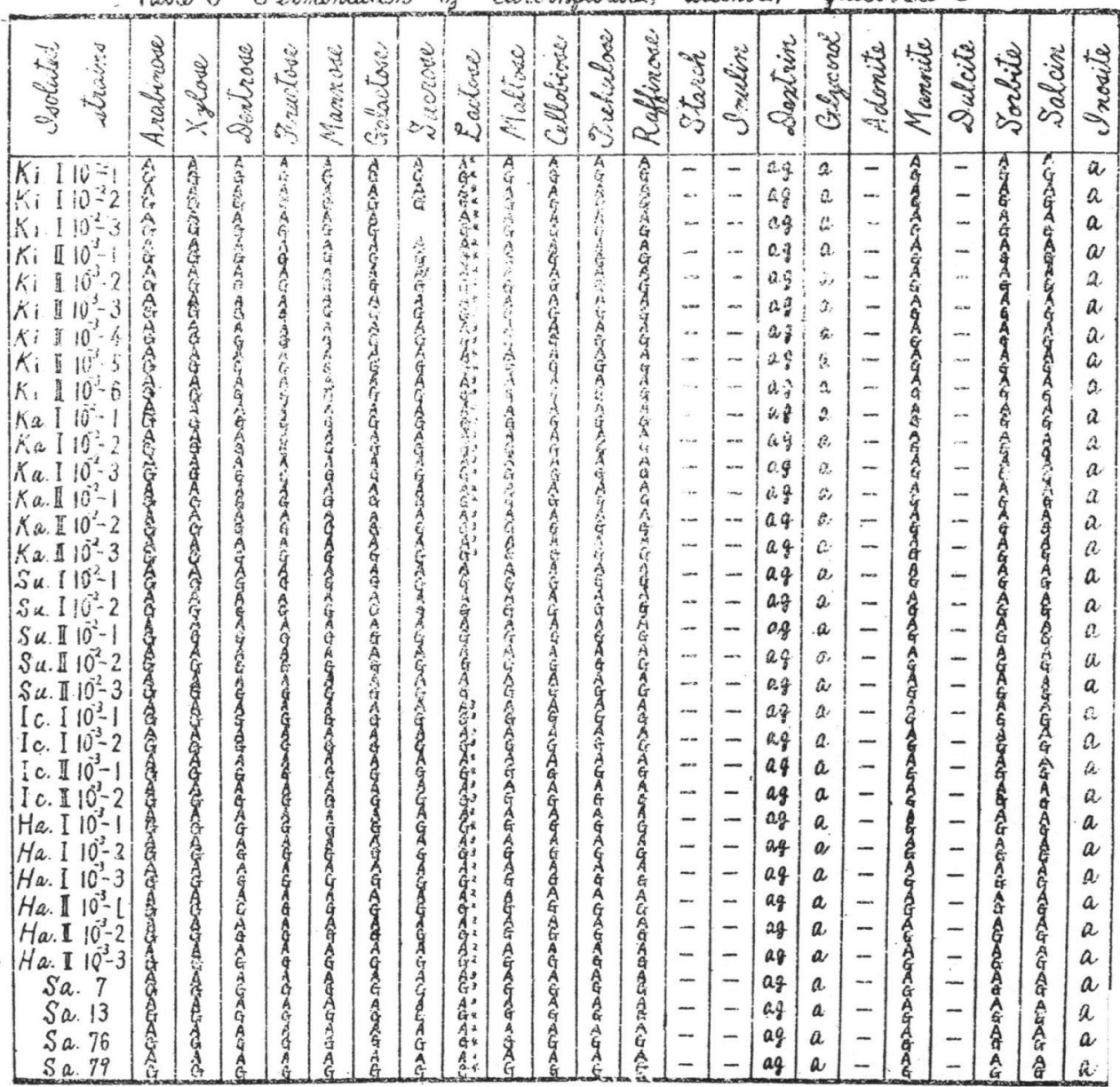

備考：表中A記号はB. T. Bの極限酸性色, G記号は瓦斯発生を示し, a記号注B.T.B.の 中間色索, $\mathrm{g}$ 記号は僅微の瓦斯発生交す。24時間内に分解せられないるの流記 号の淤上に数字を以て分解に要与る日数を附記した。

2) 中村交次：露灾医学，8，1085 (1928)

3) 井上悪政：酸酻工学椎誌，25, 145 (1948)

4) Gatin Mr. \& Mis. : Chem Abst., 2, 294 (1908) 前㽢実：東京医学会雑誌，28，321 (1914)

5) 井上囊政：栄盖研究所報告, 10卷 2号, 20 (1941)

6) Hajna, A. A., \& C. A. Perry : Sewage Works J. 10, 261 (1938)

7) Paar, L. W. : Am. J. Public Health, 26, 39 (1936)

8) Hajna, A. A., \& S. R. Damon: Am. J. Hygiene, 19, 545 (1934) 